\title{
Ten Actions to Build an Adult Basic Skills Development System That Is More Inclusive, Relevant, Efficient, and Sustained
}

Paul J. Jurmo, Independent Consultant, Basic Skills for Development

Author's Note: This article was written before recent major events (e.g., COVID-19, economic downturn, increased social justice activism, and a presidential campaign) impacted our field and nation. While time limitations don't allow me to update this document to reflect those new realities, the overall message is essentially the same: Adult learners, their families and communities, and our nation can benefit from an expanded and improved system of basic skills development opportunities. If adult educators and other stakeholders work together in thoughtful, creative ways, we can create such a system.

Since the 1980s, work-related adult basic skills programs in the United States have helped learners achieve personal goals, responded to policy requirements, and served other stakeholders including learners' families and communities, employers and labor unions, and diverse service providers. The field has also generated valuable expertise adaptable for future efforts (Bergson-Shilcock, 2019; Bragg, 2019; Mortrude, 2017). However, as a field, we are also faced with significant challenges:

- Inclusiveness: We need to more adequately reach diverse populations and other stakeholders impacted by limited basic skills (Bernstein \& Vilter, 2018; Hilliard \& Dann-Messier, 2015; McHugh \& Morawski, 2017; Patterson \& Song, 2018; Pleasants McDonnell \& Collins, 2017).

- Relevance: We need to better respond to the basic skills-related strengths, motivations, and needs of learners and other stakeholders (McHugh \& Doxsee, 2018).

- Efficiency: We need to more consistently use effective strategies customized to serve learners, manage programs, and build support (Nash \& Hewlett, 2017).

- Sustainability: Effective services must be learned from and sustained over time (Bragg, 2019; National Commission on Adult Literacy, 2008).

Observers have been raising such concerns about program quality and sustainability since the 1980s (Jurmo, 2020). Sometimes the field has adjusted policy and practice in response. However, these concerns have grown recently as poverty and other challenges (i.e., the changing world of work, declines in union membership, obstacles to integration of immigrants and former inmates into the workforce) have increased for basic-skills-limited adults. 
In one example, in response to the nationwide growth in poverty, the Open Door Collective (ODC) has made the economic security of adults with basic skills limitations a primary focus. Since its founding as a national network of adult educators and other stakeholders in 2014, ODC has produced position papers, "Can-Do Guides," and conference presentations ${ }^{1}$ showing why and how basic skills programs can collaborate with diverse stakeholders to help diverse adult learner populations (e.g., incumbent workers and job-seekers, refugees and immigrants, current and former inmates) strengthen their economic security and tackle other problems. The Migration Policy Institute and Jobs for the Future are among other organizations calling for similar supports for historically hard-to-employ individuals.

Building on this and other similar work, I propose that adult educators - in partnership with adult learners and other stakeholders - re-think the why's and how's of current adult basic skills efforts and take the following actions to make basic skills education more inclusive, relevant, efficient, and sustained.

\section{Ten Actions}

\section{Think "high-quality systems."}

The idea of building better-coordinated systems of services rather than collections of assorted (and often duplicative, confusing, or inconsistent) programs is not new. "Systems thinking" has underlain efforts to integrate basic skills education with workforce investment boards, career pathways, and other multi-service initiatives for hard-to-employ populations.

Aiming for high quality in our work has likewise been integral to systems-reform efforts like Equipped for the Future (Spangenberg \& Watson, 2003). ${ }^{2}$ Recognizing the above-described gaps in current efforts, we should now revisit how we define "quality" and emphasize inclusiveness, relevance, efficiency, and sustainability as criteria for adult basic skills systems.

\section{Re-define those we serve and how basic skills limitations can impact them.}

Discussions of "the adult basic skills problem" often focus on the limitations that adults bring with them and the personal, economic, and social costs of skills gaps. They typically overlook the rich assets that a diverse learner population brings to basic skills education: positive motivations, skills, and knowledge; support systems; and the contributions they make to their own wellbeing and that of their families, workplaces, and communities. While recognizing and building on these learner strengths, we should - respectfully and accurately - also acknowledge that basic skills limitations can reduce adults' capacity to:

- perform employment-related tasks (e.g., find, apply for, and secure jobs; perform workplace duties and participate in training; understand and protect their rights as workers; transition to retirement);

- manage family responsibilities (e.g., family health and safety, housing, financial and legal tasks, childcare);

- participate in civic roles (e.g., voting, citizenship attainment, community improvement); and,

- attain educational and occupational credentials.

1 Visit www.opendoorcollective.org for "ODC Papers" and "Resources."

2 For more about Equipped for the Future, visit https://eff.clee.utk.edu/products_services/online_publications.htm . 
While adult basic education has historically focused on individuals with basic skill gaps, we should intentionally also consider other stakeholders as potential "secondary" beneficiaries. These are groups who can both benefit from and be actively involved in basic skills efforts. They include learners' families and communities, employers and labor unions, diverse service providers, retailers, and K-12 schools (whose students need support from adult caregivers at home). In sum, a broad definition of the potential beneficiaries and purposes of adult basic education can expand the numbers of individuals and stakeholders served, broaden and deepen the relevance of services, and attract increased resources to the field.

\section{Focus on multiple, interwoven purposes for adult education.}

Job attainment can be a very worthy goal. However, an overly-narrow focus on gaining employment ignores the facts that adults must perform many other tasks to succeed in the world of work, two-thirds of those with basic skills limitations are already employed; ${ }^{3}$ and many potential learners are motivated to improve their basic skills for reasons that are not directly employment-related (e.g., helping their children succeed in school, advancing to post-secondary education, attaining citizenship).

If we want adult basic education to support the well-being (economic and otherwise) of individuals, families, communities, and the nation as a whole, we should advocate for a multi-purpose system in which adult educators and other stakeholders collaborate to help learners perform the multiple responsibilities described above.

\section{Plan with an understanding of the contexts in which learners and adult basic education practitioners operate.}

To ensure the relevance of our work, avoid obstacles, and take advantage of opportunities, we must understand the social, economic, bureaucratic, and political contexts in which we operate. For example, if we want to help learners succeed in jobs, we must know the jobs available in local industries: their advantages, limitations, and requirements; and other factors (e.g., discrimination, health, safety, transportation, housing) that can support or inhibit workplace success for workers. We should then use our understanding of these factors when planning with workforce investment boards and other entities that track such information. We should continuously monitor program impacts through classroom discussions with learners, interactions with partner agencies, and professional development activities to ensure our efforts' relevance and effectiveness.

\section{Take a comprehensive view of "basic skills."}

Our field has largely moved beyond focusing solely on "reading instruction," a holdover from when literacy was equated simply with ability to read. Since the 1970s, we have used broader terms like "basic skills" when discussing written and oral language, numeracy, digital literacy, problemsolving, collaboration, and other essential skills adults need in their varied roles. This wider focus allows us to respond to the multiple tasks learners face. But it also challenges us to integrate multiple learning objectives and services into our programs.

To more efficiently define and teach this broader mix of basic skills, we might return to the skills standards of Equipped for the Future (EFF) 
(Spangenberg \& Watson, 2003), a research-based initiative of the National Institute for Literacy. EFF identified the basic skills adults need to function in work, family, and civic roles and developed practices that adult educators can use to help various learner populations meet their full potential in these areas. The particular skills that programs focus on would vary across learners, the roles they play, the contexts they operate in, and the skills and knowledge they need to strengthen.

\section{Creatively customize and efficiently maximize services.}

Customizing services to the range of diverse learner populations, learning needs, and other stakeholders is both very important and very challenging. The good news is that our field has already developed resources we can adapt to maximize the impact and efficiency of our efforts.

For example, if we help parents develop basic skills and other assets needed to help their children succeed in school (and thereby prepare our future workforce), we will be helping two generations of learners in a cost-effective way. If we help former inmates earn a high school credential and move into post-secondary education and employment, we also support their children, who are at higher risk of poor academic performance and incarceration, and their communities by reducing the likelihood that former inmates will re-engage in crime (Peterson, Cramer, Kurs, \& Fontain, 2015). If we not only help individuals get a job but continue learning after they do so, they are more likely to retain their jobs and continue growing in their careers.

Though instruction will need to be customized to particular learners and their needs, there are many common themes that can be addressed across curricula (e.g., communicating clearly with coworkers and supervisors; managing one's finances; engaging in healthy, safe, and environmentally- friendly behaviors). Relevant teaching and learning resources and credentials can be organized in a resource collection by topics and applications, adaptable for particular learners and their needs. A candidate for a truck driver position might thus not only develop technical skills specific to operating a vehicle but also learn skills that are transferable to many jobs and life roles such as how to engage in healthy behaviors, manage personal finances, interact with customers and co-workers, and pursue further training and education.

\section{Strengthen and expand partnerships that can support programs and learners.}

Basic skills programs and learners can benefit from well-planned partnerships with a broad range of stakeholders. For example, health care professionals can provide health education and health care career training to basic skills learners and help make learning facilities more health-friendly. Adult education and health partners can also carry out joint research and advocacy activities. Employers, labor unions, environmental programs, legal services, K-12 schools, libraries, universities, and other institutions can likewise work with adult educators in productive partnerships. Those institutions, in turn, can benefit from having better access to adult learners (to enable health care providers to provide educational and other health services to individuals with limited English proficiency, for example). While establishing and maintaining collaborations require extra work for partners, such collaborations can be a win-winwin for education programs, learners, and other stakeholders.

\section{Expand when, where, and how learners can develop basic skills.}

While face-to-face instruction in learning centers will remain an important way for adults to develop 
basic skills, learners can face many barriers to using learning centers: multiple responsibilities; lack of safe, reliable transportation; remoteness from a center; long program waiting lists; curricular mismatch with learning needs; instructors whom learners are not comfortable with. Many adults might also have had negative experiences in school and be reluctant to repeat such experiences. Even when programs meet learners' needs, learners typically need more "time on task" than many centers can offer.

Adult educators should therefore consider strategies for expanding the learning opportunities available to learners. I propose adopting "learning eco-system" models already being developed in health (Ministry of Health, 2015) and workplace education (Folinsbee \& Jurmo, 1994; Hall \& Lansbury, 2006) ${ }^{4}$ in the United States and other countries, to provide learners with three learning venues:

- Learning centers: These can provide useful face-to-face supports including assessment, instruction, counseling, and referrals to other services. Centers can be based in a variety of locations to maximize convenience. Center staff can also encourage and facilitate learning outside the classroom.

- Self-directed learning: Many learners engage in self-directed (or self-study) activities to enhance their skills and/or achieve other learning goals, using various tools (e.g., print materials, video or audio recordings, informal tutoring from family or friends) (Reder \& Strawn, 2006; Sharma, Vanek, \& Ascher Webber, 2019).

- $\quad$ Situated learning: Basic skills learners can develop their basic skills, other forms of knowledge, and self-confidence through authentic practice in real-life contexts such as the workplace, the market or doctor's office, watching television, or reviewing their children's homework. Practicing and fine-tuning skills introduced in programs or in self-directed learning are vital for further building those skills and self-confidence. Though situated learning is often unconscious and unplanned, learners can be taught how to engage in authentic practice in more efficient, reflective ways. Other stakeholders (e.g., employers, health care providers, libraries, retailers) can also be shown how to make their facilities, procedures, products, and services more user-friendly for basic-skills-challenged adults.

Learners can engage in one or more of these forms of learning, moving from one to the other as time, interest, logistics, and other factors allow. Using all three formats in an intentional, organized way can enable learners to accelerate learning and get reflective practice required for mastery of basic skills. Our field already possesses many elements (e.g., formal programs, digital technologies, workplace and health literacy learning models) of this multi-venue model.

\section{Recognize adult basic skills education as a profession.}

Ironically, while adult educators are often called on to help learners move into family-sustaining jobs, there are relatively few full-time, professional positions in our own field. This contributes to high turnover, reduced program quality and quantity, and a heavy reliance on part-time and/ or volunteer staff. We should advocate for more professional staff who are given training in the demanding work of program management and 
customizing instructional and other services for varied skill areas and learner populations, career advancement opportunities, and other supports such as professional-level salaries, full-time positions, and benefits. These professionals could come from a wide range of backgrounds and provide leadership, continuity, mentoring, and other supports to learners, staff, and partners, to ensure sustained, high-quality services. ${ }^{5}$

\section{Sustain effective services.}

High-quality adult basic skills programs require supports from within their respective institutions and community, state, and national levels. These supports include policy guidelines, financial and in-kind resources, professional development, demonstration projects, resource centers, adaptable curricula and assessments, research and evaluation, and peer networks.

Many of these supports already exist (or formerly existed) through federal and state agencies; national and state associations; community-level workforce boards and health coalitions; research institutions; business and labor groups; and entities dealing with special populations or issues. These should be evaluated, learned from, built on, and better coordinated.

\section{Conclusion: Strengthened and New Leadership Needed}

I have outlined 10 actions we can take to better serve adult learners through what we might call "a work-family-community integrated adult basic skills development system." But for any of this to happen, we will continue to need strong and sustained leadership - at all levels, across stakeholders, for every system component. Leaders for this demanding but vital work need vision, technical expertise, and the ability to think and work creatively with others. Past and current effective leaders should be recognized, supported, and learned from. At the same time, new leaders should be recruited, nurtured, and sustained with the supports described above, to fill the ranks as services expand and veteran professionals move on. The case for a sustained, well-conceived investment in the development of our field has been made for decades (Council for Advancement of Adult Literacy, 2002). To keep us on track, all involved should remember that this important work can produce tremendous rewards for millions of individuals and for our country's future.

\footnotetext{
5 The June 2002 issue of Focus on Basics contains useful articles on the theme of “staff development" (http://ncsall.net/fileadmin/resources/fob/2002/fob_5d.pdf).
} 


\section{References}

Bergson-Shilcock, A. (2019). Better together: How adult education/CTE collaborations benefit workers and businesses. Washington, DC: National Skills Coalition.

Bernstein, H., \& Vilter, C. (2018). Upskilling the immigrant workforce to meet employer demand for skilled workers. Washington, DC: Urban Institute.

Bragg, D. (2019). What works for adult learners: Lessons from career pathway evaluations. Boston, MA: Jobs for the Future.

Council for Advancement of Adult Literacy (2002). Making the case: Adult education and literacy: Key to America's future. New York: Author.

Folinsbee, S., \& Jurmo, P. (1994). Collaborative workplace development: An overview. Don Mills, ON: ABC CANADA.

Hall, R., \& Lansbury, R. D. (2006). Skills in Australia: Towards workforce development and sustainable skill ecosystems. Journal of Industrial Relations, 48(5), 575-592.

Hilliard, T., \& Dann-Messier, B. (2015). Boosting adult education in New York. New York, NY: Center for an Urban Future.

Jurmo, P. (January, 2020). An archive of work-related basic skills resources. Open Door Collective (retrieved from www.opendoorcollective.org).

McHugh, M., \& Doxsee, C. (2018). English plus integration: Shifting the instructional paradigm for immigrant adult learners to support integration success. Washington, DC: Migration Policy Institute.

McHugh, M., \& Morawski, M. (2017). Unlocking skills: Successful initiatives for integrating foreign-trained immigrant professionals. Washington, DC: Migration Policy Institute.
Ministry of Health (2015). Health literacy review: A guide. Wellington, NZ: Author.

Mortrude, J. (2017). Integrated education and training: A career pathways policy and practice. Washington, DC: Center for Law and Social Policy.

Nash, A., \& Hewett, E. (2017). Integrated education and training: Implementing programs in diverse contexts. Boston, MA: National College Transitions Network.

National Commission on Adult Literacy (2008). Reach higher, America: Overcoming crisis in the U.S. workforce. New York, NY: Council for Advancement of Adult Literacy.

Patterson, M., \& Song, W. (2018). Critiquing adult participation in education, report 1: Deterrents and solutions. Media, PA: VALUEUSA.

Peterson, B., Cramer, L., Kurs, E., \& Fontain, J. (2015). Toolkit for developing family-focused jail programs. Washington, DC: Urban Institute.

Pleasants McDonnell, R., \& Collins, M. (2017). Framing the opportunity: Eight state policy recommendations that support postsecondary credential completion for underserved populations. Boston, MA: Jobs for the Future.

Reder, S., \& Strawn, C. (2006). Self-study: Broadening the concepts of participation and program support. Focus on Basics, 8(C), 6-10.

Sharma, P., Vanek, J., \& Ascher Webber, A. (March, 2019). Leveraging technology to increase opportunity and economic security for adults: Field testing tools that break barriers to learning and employment. Boston, MA: EdTechCenter and JFF Labs.

Spangenberg, G., \& Watson, S. (2003). Equipped for the future: Tools and standards for building and assessing quality adult literacy programs. New York, NY: Council for Advancement of Adult Literacy. 